\title{
The rapid identification of Acinetobacter species using Fourier transform infrared spectroscopy
}

\author{
C.L. Winder ${ }^{1}$, E. Carr ${ }^{2}$, R. Goodacre ${ }^{1}$ and R. Seviour ${ }^{2}$ \\ ${ }^{1}$ Department of Chemistry, UMIST, Sackville Street, Manchester, UK, and ${ }^{2}$ Biotechnology Research Centre, La Trobe University \\ Bendigo, Bendigo, Victoria, Australia
}

2003/0194: received 6 March 2003, revised and accepted 14 October 2003

ABSTRACT
C.L. WINDER, E. CARR, R. GOODACRE AND R. SEVIOUR. 2003.

Aims: Fourier transform infrared (FT-IR) was used to analyse a selection of Acinetobacter isolates in order to determine if this approach could discriminate readily between the known genomic species of this genus and environmental isolates from activated sludge.

Methods and Results: FT-IR spectroscopy is a rapid whole-organism fingerprinting method, typically taking only 10 s per sample, and generates 'holistic' biochemical profiles (or 'fingerprints') from biological materials. The cluster analysis produced by FT-IR was compared with previous polyphasic taxonomic studies on these isolates and with 16S-23S rDNA intergenic spacer region (ISR) fingerprinting presented in this paper. FT-IR and 16S-23S rDNA ISR analyses together indicate that some of the Acinetobacter genomic species are particularly heterogeneous and poorly defined, making characterization of the unknown environmental isolates with the genomic species difficult. Conclusions: Whilst the characterization of the isolates from activated sludge revealed by FT-IR and 16S-23S rDNA ISR were not directly comparable, the dendrogram produced from FT-IR data did correlate well with the outcomes of the other polyphasic taxonomic work (E.L. Carr, P. Kämpfer, B.K.C. Patel, V. Gürtler and R.J. Seviour, 2003, International Fournal of Systematic and Evolutionary Microbiology 53, 953-963).

Significance and Impact of the Study: We believe it would be advantageous to pursue this approach further and establish a comprehensive database of taxonomically well-defined Acinetobacter species to aid the identification of unknown strains. In this instance, FT-IR may provide the rapid identification method eagerly sought for the routine identification of Acinetobacter isolates from a wide range of environmental sources.

Keywords: 16S rDNA sequencing, Acinetobacter, Fourier transform infrared spectroscopy.

\section{INTRODUCTION}

The important role that many of the genomic species of Acinetobacter play in nosocomial infections, together with their ability to develop resistance to many of the commonly used antibiotics (Towner 1997) makes rapid, reliable epidemiological typing of these organisms a necessity. Typing not only allows differentiation between epidemic and sporadic strains, but can also provide valuable epidemiological

Correspondence to: R. Goodacre, Department of Chemistry, UMIST, PO Box 88, Sackville Street, Manchester M60 1QD, UK (e-mail: r.goodacre@umist.ac.uk). information about the geographical spread and pathogenicity of particular strains of interest (Dijkshoorn 1996). This information may prove invaluable in developing strategies to prevent the spread of infections caused by Acinetobacter species. For this reason, a number of phenotypic and genotypic techniques have been applied to characterize and type clinical isolates of Acinetobacter species, with a view to identifying them reliably at the subspecies level. Unfortunately, a single technique is not universally accepted or applied in clinical laboratories for the rapid identification of strains, because the majority of the techniques produce different classifications. For example, Vila et al. (1994) used 
four typing methods to characterize two strains of Acinetobacter baumannii and strains of Acinetobacter isolated from an infectious outbreak. All the strains were previously demonstrated to have the same ribotype. However, the four typing methods indicated the strains to be quite different to each other. Thus a polyphasic taxonomic approach (Vandamme et al. 1996) should be adopted where a combination of typing methods (including at least one molecular method), are used before indistinguishable isolates are designated as the same strain (Dijkshoorn 1996). Some molecular techniques used for typing Acinetobacter strains are claimed to provide reproducible and discriminatory results (e.g. ribotyping, pulsed-field gel electrophoresis and amplified fragment length polymorphisms). However, these methods are laborious, slow, expensive and often require considerable technical expertise. Therefore, they are deemed unattractive for routine application in busy clinical laboratories. Consequently, it would be very advantageous to have a rapid typing method, which provides the reliable identification of both clinical and environmental strains of Acinetobacter. It is considered that this would greatly assist in the understanding of the ecology of members of this genus.

Whole-organism fingerprinting (Magee 1993; Goodacre et al. 1998) by physico-chemical spectroscopic methods such as pyrolysis mass spectrometry (PyMS; Goodacre and Kell 1996), Fourier transform infrared spectroscopy (FT-IR; Helm et al. 1991; Naumann et al. 1991a,b) and Raman spectroscopy (Maquelin et al. 2002) seem to represent attractive alternative identification methods, because they do not demonstrate the problems associated with genotypic typing methods. That is to say, they are rapid, require minimal sample preparation, are relatively inexpensive and can be readily automated to handle large sample numbers (Goodacre et al. 1998). Moreover, Stackebrandt et al. (2002) especially highlighted these techniques as developments of particular interest in prokaryotic systematics.

PyMS and FT-IR spectroscopy both measure the phenotype of an organism and provide a 'snap-shot' of its expressed genotype (Timmins et al. 1998a). Unlike PyMS which predominantly measures the bond strengths of molecules, FT-IR spectroscopy measures vibrations of functional chemical groups and highly polar bonds, therefore, the 'fingerprints' generated by this method consist of the vibrational features of all the cell components (e.g. DNA, RNA, proteins and lipids; Naumann et al. 1994). This method enables the generation of distinct chemical fingerprints of micro-organisms, without their destruction, and appears to have sufficient resolving power to distinguish
Table 1 Details of the known genomic species used in this study

\begin{tabular}{|c|c|c|}
\hline $\begin{array}{l}\text { Abbreviation } \\
\text { used in study }\end{array}$ & Species name & Origin/Culture Collection numbers \\
\hline BG1 & Acinetobacter calcoaceticus & ATCC $23055 \mathrm{~T} / \mathrm{CIP}$ 81.08T \\
\hline BG2 & Acinetobacter baumannii & ATCC $19606 \mathrm{~T} / \mathrm{CIP} 70 \cdot 34 \mathrm{~T}$ \\
\hline BG3 & Acinetobacter sp. 3 & ATCC 19004/CIP 70.29 \\
\hline BG4 & Acinetobacter haemolyticus & ATCC $17906 \mathrm{~T} / \mathrm{CIP} 64 \cdot 3 \mathrm{~T}$ \\
\hline BG5 & Acinetobacter junii & ATCC $17908 \mathrm{~T} / \mathrm{CIP} 64 \cdot 5 \mathrm{~T}$ \\
\hline BG6 & Acinetobacter sp. 6 & ATCC $17979 /$ CIP A165 \\
\hline BG7 & Acinetobacter johnsonii & ATCC 17909T/CIP64.6T \\
\hline BG8 & Acinetobacter lmoffii & ATCC $17925 \mathrm{~T} / \mathrm{CIP} 64 \cdot 10 \mathrm{~T}$ \\
\hline BG9 & Acinetobacter sp. 9 & ATCC 9957/CIP 70·31 \\
\hline BG10 & Acinetobacter sp. 10 & ATCC $17924 / \mathrm{CIP} 70 \cdot 12$ \\
\hline BG11 & Acinetobacter sp. 11 & ATCC $11171 /$ CIP 63.46 \\
\hline BG12 & Acinetobacter radioresistens & SEIP $12 \cdot 81$ \\
\hline BJ13 & Acinetobacter sp. 13 & ATCC $17905 /$ CIP $64 \cdot 2$ \\
\hline BJ14 & Acinetobacter sp. 14 & K.Irino 105/85 \\
\hline BJ15 & Acinetobacter sp. 15 & M.M. Adam Ac606 180 : 40va \\
\hline BJ16 & Acinetobacter sp. 16 & ATCC $17988 / \mathrm{CIP} 70 \cdot 18$ \\
\hline BJ17 & Acinetobacter sp. 17 & SEIP Ac87.314 \\
\hline TU13(ATTC) & Acinetobacter sp. 13 & ATCC 17903 \\
\hline TU13 (165) & Acinetobacter sp. 13 & Lund University \\
\hline TU14 & Acinetobacter sp. 14 & ATCC 151a1 \\
\hline TU15 & Acinetobacter sp. 15 & ATCC 71 \\
\hline CTTU13 & 'Close to TU13' & Statens Serum Institut \\
\hline $\mathrm{B} / \mathrm{W} 1+3$ & 'Between BG1 and BG3' & Statens Serum Institut \\
\hline
\end{tabular}

ATCC, American Type Culture Collection (Maryland, USA); CIP, Collection de I'Institut Pasteur (Paris); SEIP, Collection du Service des Enterobacteries, Institut Pasteur (Paris). 
microbes to strain level (Helm et al. 1991; Naumann et al. 1991b; Sandt et al. 2003). Indeed, it has sufficient resolution power to distinguish between single-gene knock-out mutants in yeast (Oliver et al. 1998).

By contrast to FT-IR, PyMS has been shown to suffer from lack of reproducibility because of instrument drift problems (Shute et al. 1988; Goodacre and Kell 1996). Coupled with the findings that PyMS and FT-IR give very similar microbial classifications (Timmins et al. 1998a,b), we believe that FT-IR is a particularly robust and reproducible whole-organism fingerprinting method. The aim of the present study was to apply FT-IR spectroscopy to the characterization of a selection of Acinetobacter isolates in order to determine if this approach could discriminate readily between the known genomic species of this genus and environmental isolates from activated sludge. The results from the FT-IR analysis were compared with those obtained using the molecular techniques of $16 \mathrm{~S}-23 \mathrm{~S}$ rDNA intergenic spacer region (ISR) fingerprinting.

\section{MATERIALS AND METHODS}

\section{Cultivation of Acinetobacter isolates for FT-IR spectroscopy}

The strains for the FT-IR analysis were selected in order to represent all the known genomic species of Acinetobacter with the exception of the recently described species A. schindleri and A. ursingii (Nemec et al. 2001; Table 1). In addition, 43 isolates from activated sludge were included in this study, including the seven newly described species (Carr et al. 2003) detailed in Table 2. The selected isolates were previously analysed by PyMS (Carr et al. 2001a).

All strains were cultured on R2A medium (Reasoner and Geldreich 1985) and incubated at $30^{\circ} \mathrm{C}$ for $24 \mathrm{~h}$. Isolates were subcultured three times in triplicate before FT-IR analysis was performed, in order to minimize possible phenotypic variation.

\section{FT-IR analysis of Acinetobacter isolates}

Bacterial cells of each isolate were harvested from agar plates by washing them with $400 \mu \mathrm{l}$ physiological saline $(0.9 \%$ $\mathrm{NaCl}$ ) and were gently mixed to produce an emulsion, which was stored on ice until required. A $10 \times 10-\mathrm{cm}$ aluminium plate was rinsed with acetone and dried at $50^{\circ} \mathrm{C}$ for $10 \mathrm{~min}$. FT-IR analysis was initially performed on the plate without samples to provide a reference reading for each well. The plate was loaded onto the motorized stage of a reflectance thin-layer chromatography accessory (Glauninger et al. 1990; Bouffard et al. 1994; Goodacre et al. 1996; Winson et al. 1997), attached to a Bruker IFS28 FT-IR spectrometer (Bruker Spectrospin Ltd, Conventry, UK). This was
Table 2 The activated sludge isolates of Acinetobacter investigated in this study along with their Biolog identifications

\begin{tabular}{|c|c|c|}
\hline $\begin{array}{l}\text { Acinetobacter } \\
\text { strain name }\end{array}$ & $\begin{array}{l}\text { Biolog } \\
\text { identification }\end{array}$ & Culture collection number \\
\hline 7B02 & $\mathrm{UN}$ & DSMZ 14966/CIP 107466 \\
\hline AB2010 & BG5 & NA \\
\hline AB2104 & BG5 & NA \\
\hline $2 \mathrm{~B} 07$ & BG7 & NA \\
\hline $6 \mathrm{~A} 07$ & BG7 & NA \\
\hline $\mathrm{M} 10 / 15$ & BG5 & NA \\
\hline C5 & $\mathrm{UN}$ & DSMZ 14963/CIP 107473 \\
\hline $4 \mathrm{~B} 02$ & $\mathrm{UN}$ & DSMZ 14964/CIP 107468 \\
\hline $5 \mathrm{~N} 13$ & $\mathrm{UN}$ & NA \\
\hline $3 \mathrm{~A} 02$ & $\mathrm{UN}$ & NA \\
\hline $6 \mathrm{~A} 05$ & $\mathrm{UN}$ & NA \\
\hline $12 \mathrm{~A} 02$ & $\mathrm{UN}$ & NA \\
\hline 21B02 & $\mathrm{UN}$ & NA \\
\hline 17A04 & $\mathrm{UN}$ & DSMZ 14968/CIP 107470 \\
\hline A7 & $\mathrm{UN}$ & DSMZ 14959/CIP 107476 \\
\hline 1SRO6 & BG7 & NA \\
\hline $\mathrm{C} 1$ & $\mathrm{UN}$ & NA \\
\hline 9B03 & BG7 & NA \\
\hline $26 \mathrm{~N} 03$ & $\mathrm{UN}$ & NA \\
\hline $5 \mathrm{~B} 02$ & BG9 & DSMZ 14965/CIP 107467 \\
\hline 7N16 & $\mathrm{UN}$ & DSMZ 14971/CIP 107465 \\
\hline $5 \mathrm{~N} 03$ & BG2 & NA \\
\hline AB3316 & BG5 & NA \\
\hline AB1030 & BG5 & NA \\
\hline $6 \mathrm{~N} 01$ & BG7 & NA \\
\hline $1 \mathrm{~A} 08$ & BG7 & NA \\
\hline $11 \mathrm{~N} 04$ & BG7 & NA \\
\hline 9A01 & $\mathrm{UN}$ & DSMZ 14967/CIP 107464 \\
\hline $11 \mathrm{~A} 04$ & BG7 & NA \\
\hline 22B02 & BG12 & NA \\
\hline 26B02 & BG12 & NA \\
\hline $2 \mathrm{~N} 01$ & BG12 & DSMZ 14969/CIP 107471 \\
\hline 6N03 & BG7 & NA \\
\hline $\mathrm{A} 23$ & $\mathrm{UN}$ & DSMZ 14960/CIP 107475 \\
\hline D11 & $\mathrm{UN}$ & NA \\
\hline $25 \mathrm{~A} 01$ & BG7 & NA \\
\hline AB1141 & BG8/9 & NA \\
\hline AB1110 & BG7 & DSMZ 14962/CIP 107472 \\
\hline 19A01 & BG7 & NA \\
\hline AB1160 & BG5 & NA \\
\hline $4 \mathrm{~N} 13$ & $\mathrm{UN}$ & DSMZ 14670/CIP 107469 \\
\hline $\mathrm{B} 2$ & $\mathrm{UN}$ & DSMZ 14961/CIP 107474 \\
\hline $\mathrm{J} 22 / 15$ & BG10 & NA \\
\hline
\end{tabular}

UN, unidentified; NA, not applicable; DSMZ, Deutsche Sammlung von Mikroorganismen und Zellkulturen; CIP, Collection de I'Institut Pasteur, Paris.

equipped with a mercury-cadmium-telluride (MCT) detector, which was cooled with liquid $\mathrm{N}_{2}$. A $10-\mu$ l aliquot of each sample was evenly applied in triplicate onto the 100-well plate (so called machine replicates). The plate was then 
Fig. 1 Typical FT-IR spectra of both the environmental (7B02) and known genomic species (BG14) of Acinetobacter

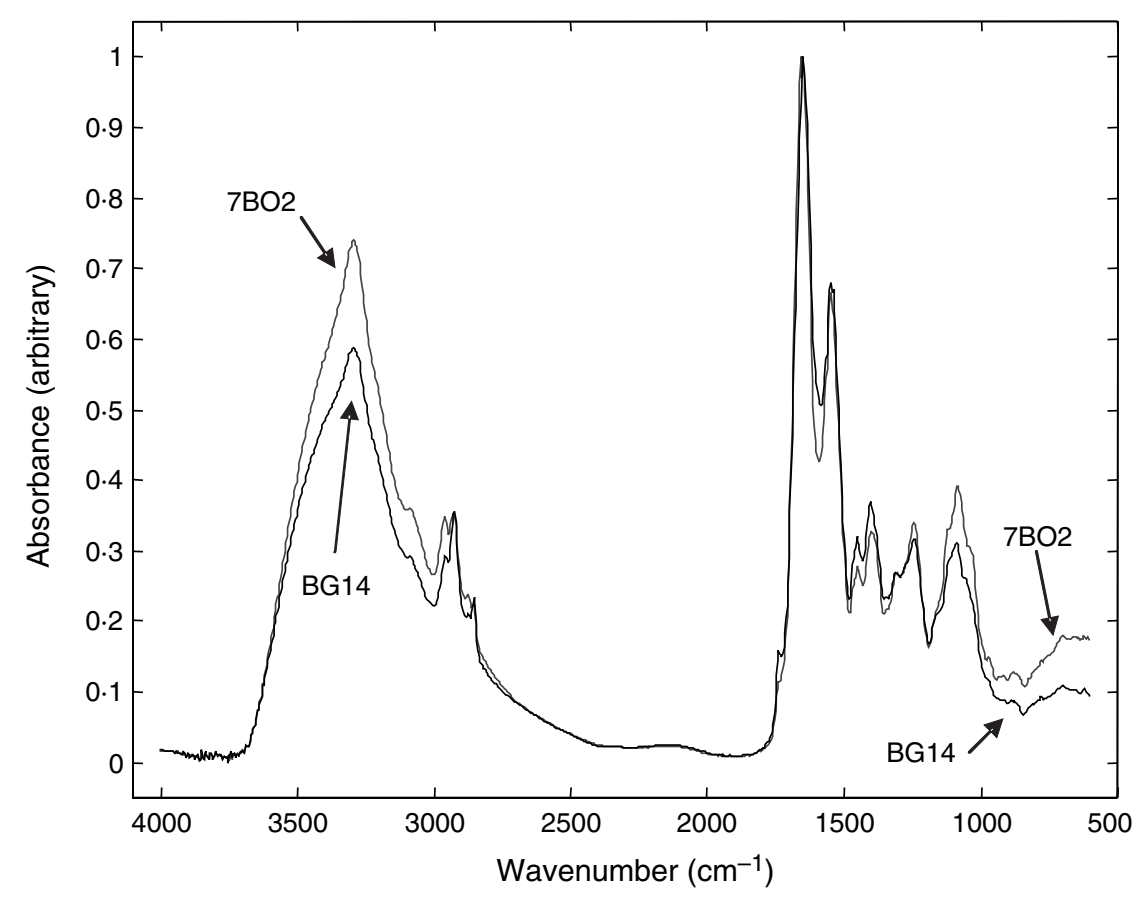

dried at $50^{\circ} \mathrm{C}$ for $30 \mathrm{~min}$ before FT-IR analysis was performed. Spectra were collected over the wavelength range of 4000 to $600 \mathrm{~cm}^{-1}$ under the control of an IBM-compatible computer (Dell Computer Corporation, Bracknell, UK) programmed with Opus 2.1 running under IBM OS/2 Warp, which was provided by the manufacturers. Spectra were acquired at a rate of $20 \mathrm{~s}^{-1}$, with a resolution of $4 \mathrm{~cm}^{-1}$, so that each sample represents a spectrum containing 882 data points. To improve the signal-to-noise ratio, 256 spectra were co-added and averaged. The spectra are displayed in terms of absorbance (see Fig. 1 for typical spectra), which was calculated from the reflectance-absorbance spectra using OPUS software (Bruker Spectrospin Ltd).

The ASCII data were imported into Matlab ver. 5 (The MathWorks, Inc., Natick, MA, USA). To minimize problems arising from baseline shifts Matlab was used to correct for $\mathrm{CO}_{2}$ vibrations (the $\mathrm{CO}_{2}$ peaks at $2403-2272 \mathrm{~cm}^{-1}$ and $683-656 \mathrm{~cm}^{-1}$ were removed, and filled with a trend) and the data were normalized such that the smallest recorded absorbance was set to 0 and the highest was set to 1 for each spectrum. Principal components analysis (PCA; Jolliffe 1986) was performed on the spectra to reduce the dimensionality of the multivariate data prior to discriminant function analysis (DFA). DFA discriminates between groups on the basis of the retained principal components with a priori knowledge of which spectra were replicates (MacFie et al. 1978; Windig et al. 1983) and minimizes 'within group' variance and maximizes 'between group' variance. As this was based on the machine replicates this does not bias the analysis in any way. Finally, hierarchical cluster analysis (HCA) was used to construct a dendrogram from the a priori group centres in DFA space using Euclidean distances as described by Goodacre et al. (1998) and the dendrogram was produced using average linkage clustering algorithm (Manly 1994).

\section{RESULTS}

All samples gave reproducible characteristic biological infrared absorption spectra (see Fig. 1 for examples). However, the spectra and all the others collected have complex and broad contours with little qualitative difference between them, although on closer inspection quantitative differences can be observed. Such spectra, essentially un-interpretable by the naked eye, demonstrate the need to use multivariate statistical methods for the analyses of these data.

DFA was performed on these spectra and the resultant plot of discriminant function (DF) 1 vs DF 2 is given in Fig. 2. The relationship between the known genomic species strains is observed more readily when only the a priori group centres in the DFA space are plotted (Fig. 2b) and some clustering is observed. For example, the strains representing the genomic species TU13, TU14 and TU15 of Tjernberg and Ursing (1989) cluster together, as do strains BJ14 and BJ17 of Bouvet and Jeanjean (1989), however, the strains of BJ15 and BJ16 cluster elsewhere. The strains of the 12 genomic species described by Bouvet and Grimont (1986) are recovered in several separate clusters in the DFA plot. Thus whilst the strains of BG2, 

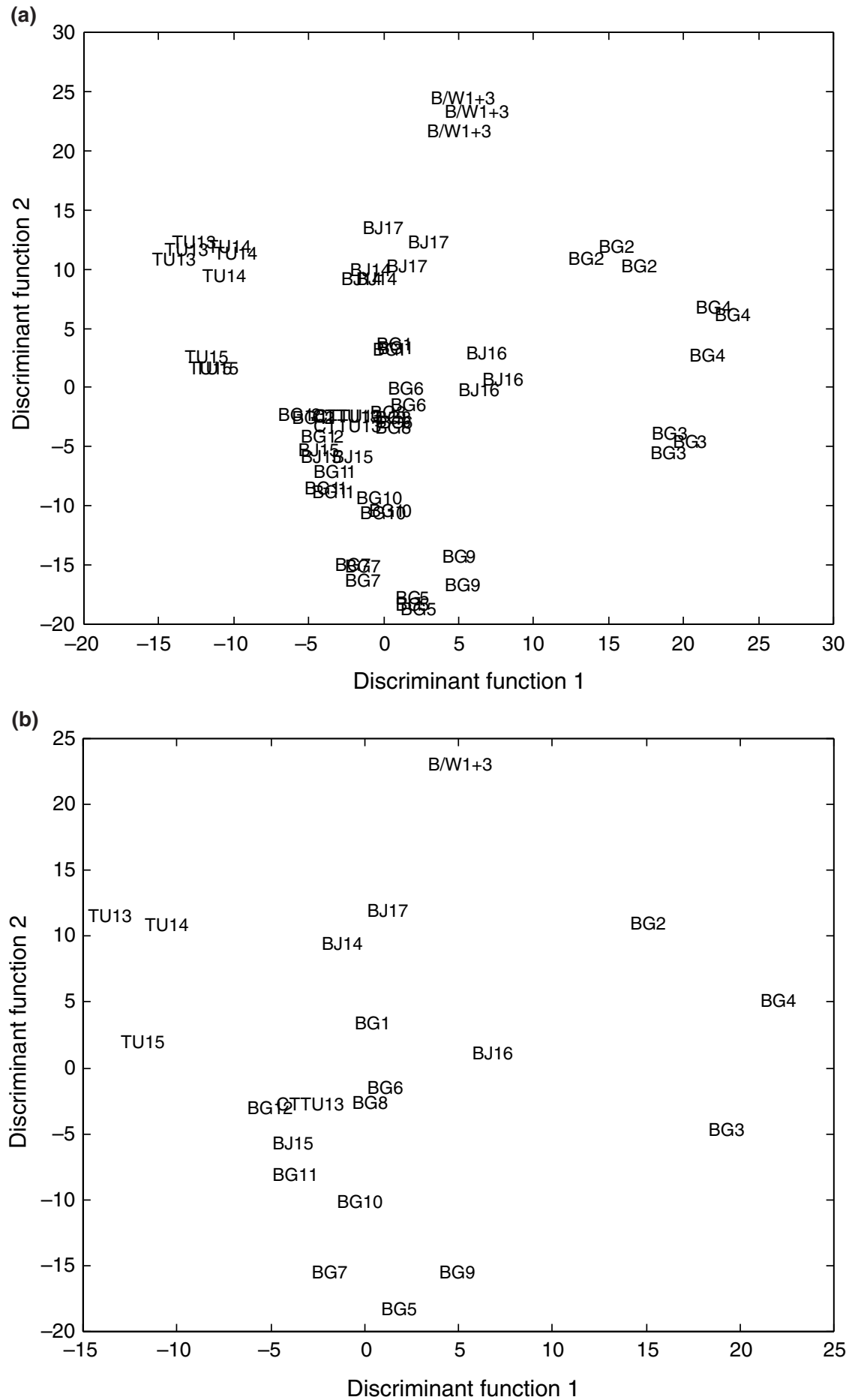

Fig. 2 Discriminant function analysis plot based on FT-IR data of the known genomic species of Acinetobacter. (a) The three machine replicates are plotted. (b) The group centres of the machine replicates are plotted
BG3 and BG4 are recovered together, as are BG5, BG7 and BG9, strains of the other BG genomic species (BG1, BG6, BG8, BG10, BG11 and BG12) are dispersed through the DFA cluster space.

Fourty-three activated sludge isolates of Acinetobacter were selected for analysis by FT-IR. The vast majority of the environmental isolates and genomic species clustered in one large group with several outliers (Fig. 3). The relationships between the strains are perhaps better illustrated using HCA analysis of the FT-IR data (Fig. 4). In general, the majority of the activated sludge isolates failed to cluster closely with strains of the known genomic species after 
Fig. 3 Discriminant function analysis plot based on FT-IR data of both environmental isolates and known genomic species of Acinetobacter

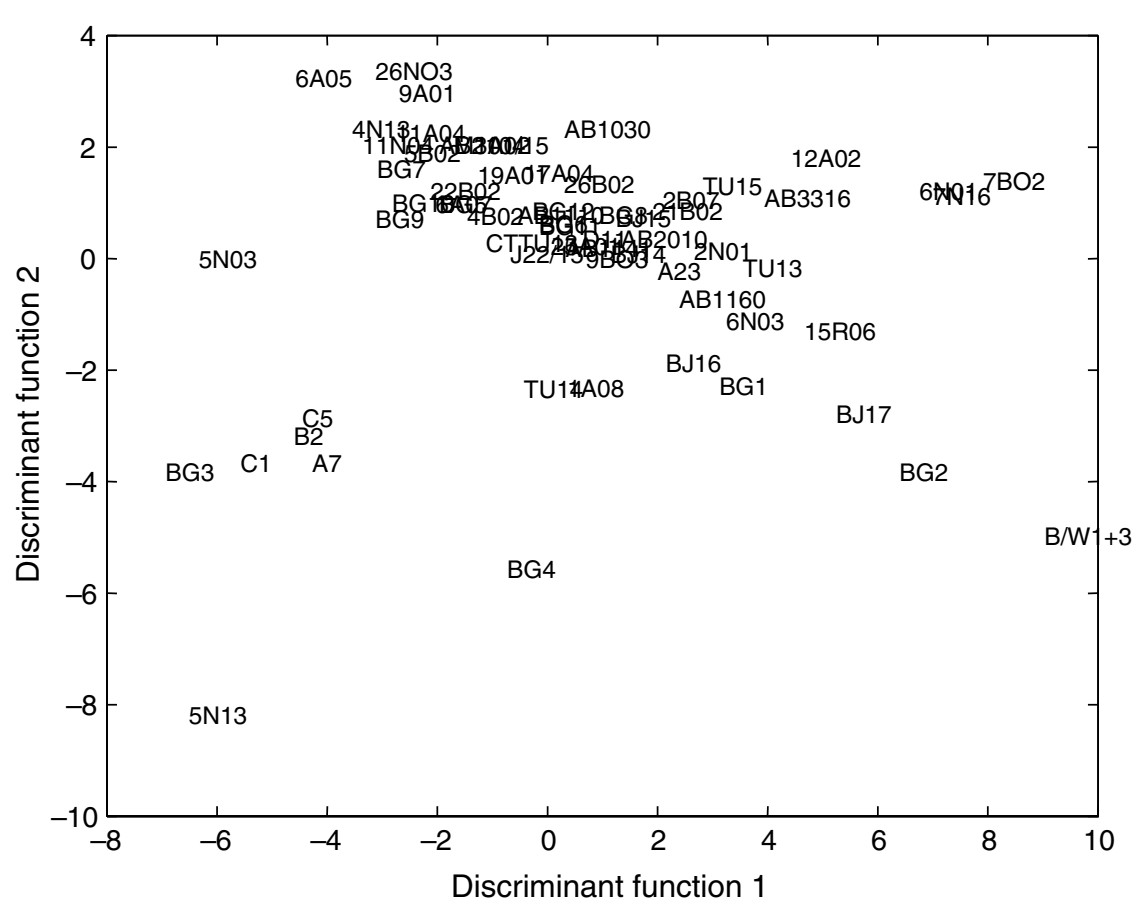

FT-IR analysis. However, some exceptions were observed. For example, strains BG5 and 22B02, BG7 and 11N04, and BG11 and AB1110 all cluster very closely together and BG3 clusters with the four environmental isolates B2, A7, C5 and C1.

\section{DISCUSSION}

\section{Analysis of the known genomic species of Acinetobacter by FT-IR spectroscopy}

These findings from FT-IR analysis do not wholly agree with those suggested from earlier DNA-DNA hybridization data (Bouvet and Grimont 1986; Bouvet and Jeanjean 1989; Tjernberg and Ursing 1989). For example, FT-IR failed to group BG8 and BG9 together, whilst DNA-DNA hybridization illustrated the two samples to be taxonomically very similar (Bouvet and Grimont 1986; Tjernberg and Ursing 1989). The FT-IR analysis indicates that the 12 genomic species described by Bouvet and Jeanjean (1989) to be heterogenous because they are recovered throughout the DFA space. However, separation of the two genomic BG 8 and BG9 by FT-IR was not surprising, because they can also be distinguished from each other when characterized by other techniques (Wiedmann-Al-Ahmad et al. 1994; Carr et al. 2001a,b), hence, reinforcing the accepted problems using DNA-DNA hybridization as a method for determining speciation in bacteria (Stackebrandt et al. 2002). Likewise, strains of the genomic species BG1, BG2, BG3, TU13,
CTTU13 and $\mathrm{B} / \mathrm{W} 1+3$ belonging to the $A c b$ complex (Gerner-Smidt et al. 1991) did not cluster together by FT-IR analysis, by contrast $16 \mathrm{~S}-23 \mathrm{~S}$ rDNA fingerprinting (Carr et al. 2001a) groups all these species closely together, with the exception of TU13. However, both methods grouped TU13 with TU14 (Fig. 2b).

Characterization of the known genomic species of Acinetobacter by PyMS indicated that BG1 and BG2 had very similar fingerprints. However, a direct comparison between the PyMS and FT-IR data is complicated by the omission of some members of the $A c b$ complex in the PyMS analysis (Carr et al. 2001a). The phenotypic similarity of the organisms belonging to this complex is well documented (e.g. Gerner-Smidt et al. 1991) and causes great difficulties in the typing of this complex by clinical laboratories. FT-IR and PyMS analysis (Carr et al. 2001a) grouped BJ14 and BJ17 together. However, strains of the other proteolytic genomic species (BJ15 and BJ16) of Bouvet and Jeanjean (1989) were recovered separately. The $16 \mathrm{~S}-23 \mathrm{~S}$ rDNA ISR fingerprinting (Carr et al. 2001a) and 16S rDNA sequencing (Ibrahim et al. 1997) grouped BJ15, BJ16 and BJ17 together, but not BJ14. Strains BG10 and BG11 were recovered in the same cluster as BJ15 by FT-IR analysis, this may be expected from DNA-DNA hybridization data, which indicates that BG11 is more similar to BJ15. These observations are perhaps not surprising when considering the findings from the genomic fingerprinting methods (Wiedmann-Al-Ahmad et al. 1994; Vaneechoutte et al. 1995; Janssen et al. 1997). 


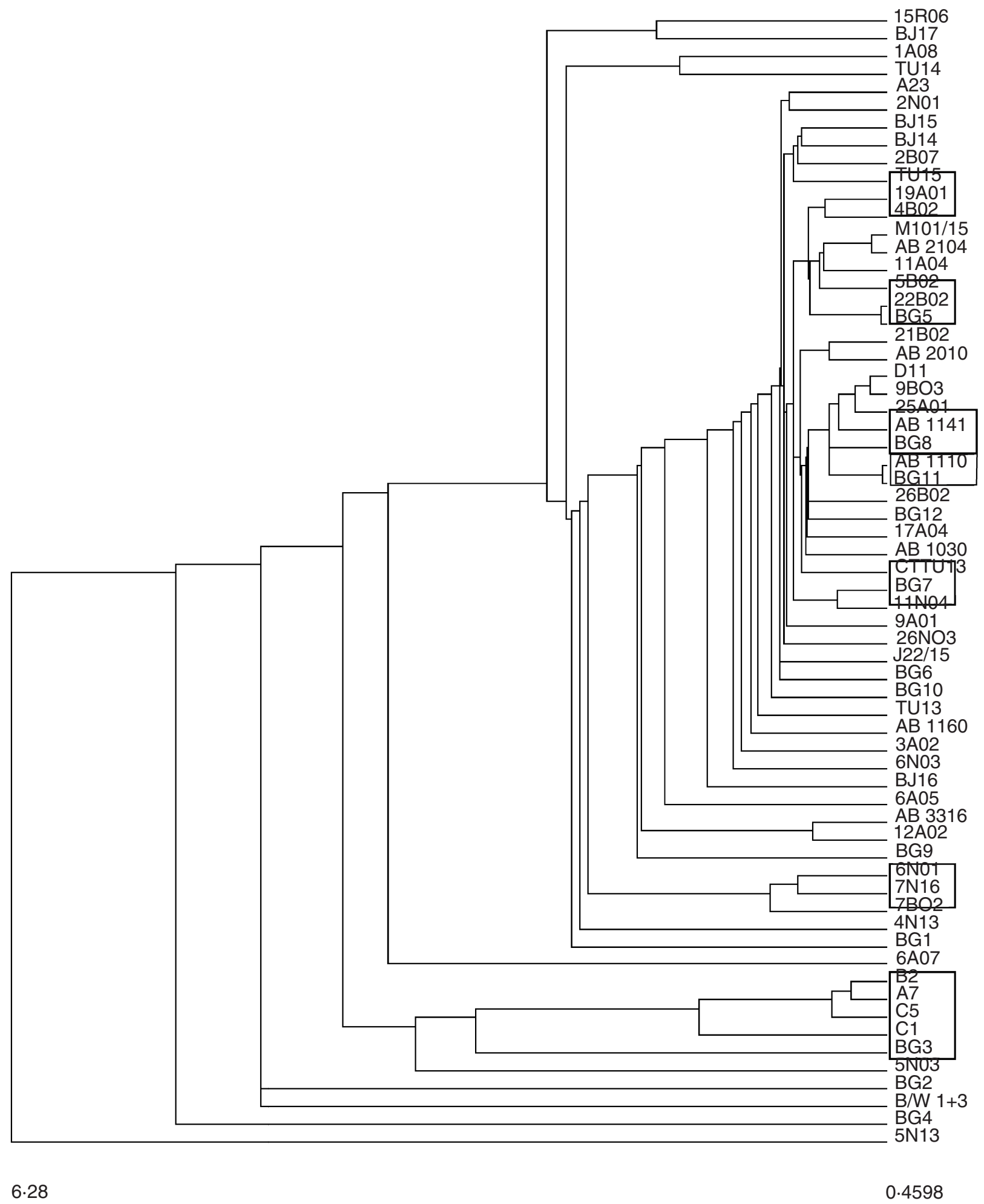

Fig. 4 Dendrogram based on FT-IR data showing the relationships between the environmental and known genomic species of Acinetobacter generated by hierarchical cluster analysis 
Table 3 Comparison of various techniques to identify a sub-set of Acinetobacter strains

\begin{tabular}{|c|c|c|c|c|c|c|c|c|}
\hline \multirow[b]{3}{*}{ Reference } & \multicolumn{8}{|c|}{ Characterization technique } \\
\hline & \multirow{2}{*}{$\begin{array}{l}\text { 16S-23S } \\
\text { rRNA ISR }\end{array}$} & \multicolumn{3}{|l|}{ PyMS* } & \multirow[b]{2}{*}{ FT-IR } & \multirow[b]{2}{*}{ RAPD-PCR $\dagger$} & \multirow[b]{2}{*}{ DNA-DNA $\ddagger$} & \multirow[b]{2}{*}{$16 \mathrm{~S}$ rRNA } \\
\hline & & Run A & Run B & Run C & & & & \\
\hline BG3 & A & A & & & $\mathrm{E}$ & B2 & A2 & \\
\hline BG8 & A & $\mathrm{D}$ & & & A & B2 & & \\
\hline BG10 & A & & & & & B1 & A2 & $\mathrm{C} 1$ \\
\hline BG11 & A & $\mathrm{B}$ & & & A & A1 & B2 & $\mathrm{C} 1$ \\
\hline A23 & A & & & & & A1 & B4 & $\mathrm{C} 1$ \\
\hline D11 & A & & & & $\mathbf{A}$ & A2 & & \\
\hline BG5 & B1 & B & & & $\mathrm{B}$ & $\mathrm{D}$ & & \\
\hline $25 \mathrm{~A} 01$ & B1 & G & & & A & & & \\
\hline BJ13 & B1 & B & & & & B2 & & D2 \\
\hline BJ15 & B1 & $\mathrm{E}$ & & & $\mathrm{C}$ & A2 & & D2 \\
\hline BJ16 & B1 & $\mathrm{C}$ & & & & B1 & B4 & D2 \\
\hline 6N01 & B1 & $\mathrm{F}$ & & & D & & & \\
\hline TU15 & B1 & & & & $\mathrm{C}$ & B2 & A3 & $\mathrm{C} 2$ \\
\hline $4 \mathrm{~N} 13$ & B1 & & $\mathrm{C}$ & & & & B3 & D2 \\
\hline $7 \mathrm{~N} 16$ & B1 & & D & & D & & & D2 \\
\hline 7B02 & B1 & & D & & D & & & D2 \\
\hline BJ17 & B2 & & & & & & B4 & D2 \\
\hline TU13 & B2 & & & & & A2 & A3 & $\mathrm{C} 2$ \\
\hline TU14 & B2 & & & & & $\mathrm{D}$ & A3 & \\
\hline BG12 & B2 & $\mathrm{D}$ & & & A & B2 & & \\
\hline AB2104 & $\mathrm{C}$ & & B2 & & $\mathrm{B}$ & & & \\
\hline 2B07 & C & G & & & C & & & \\
\hline $11 \mathrm{~A} 04$ & $\mathrm{C}$ & C & & & B & & & \\
\hline 9B03 & C & $\mathrm{F}$ & & & A & & & \\
\hline AB1110 & $\mathrm{D}$ & $\mathrm{F}$ & & & A & & B1 & C1 \\
\hline A23 & $\mathrm{D}$ & $\mathrm{E}$ & & & B & & A1 & \\
\hline AB1141 & $\mathrm{E}$ & & & F & A & & & \\
\hline 22B02 & $\mathrm{E}$ & & & $\mathrm{E}$ & B & & & \\
\hline 17A04 & $\mathrm{E}$ & & & F & A & & B4 & $\mathrm{C} 2$ \\
\hline BG7 & $\mathrm{F}$ & A & & & & B2 & & \\
\hline $5 \mathrm{~B} 02$ & $\mathrm{~F}$ & & & B1 & B & & B1 & $\mathrm{C} 2$ \\
\hline C5 & G & & & & E & C2 & A1 & C1 \\
\hline B2 & G & & & & E & C1 & A1 & C1 \\
\hline A7 & G & & & & E & $\mathrm{C} 1$ & A1 & C1 \\
\hline $\mathrm{C} 1$ & G & & & & E & C2 & & \\
\hline BG9 & & B & & & & B2 & & B \\
\hline BJ14 & & & & & C & B2 & & D2 \\
\hline 4B02 & & & & & B & & B4 & D1 \\
\hline
\end{tabular}

Characters in bold indicate a correlation of clustered strains between the individual technique and 16S-23S rRNA ISR.

*Run A, B and C refers to three samples run during the acquisition of PyMS data; Carr et al. (2001a).

$\dagger$ Carr et al. (2001b).

†Carr et al. (2003).

\section{Characterization of activated sludge isolates of Acinetobacter by FT-IR spectroscopy}

The activated sludge isolates for the study were selected on the basis of the PyMS screening and 16S-23S rDNA ISR fingerprinting (Carr et al. 2001a). The clustering pattern observed in the DFA resembles that observed in the ball and stick diagrams from the PyMS analysis of these activated sludge isolates previously reported (Carr et al. 2001a), in which the vast majority of the strains clustered in one large group, but with several outliers. The majority of strains could not be confidently assigned 


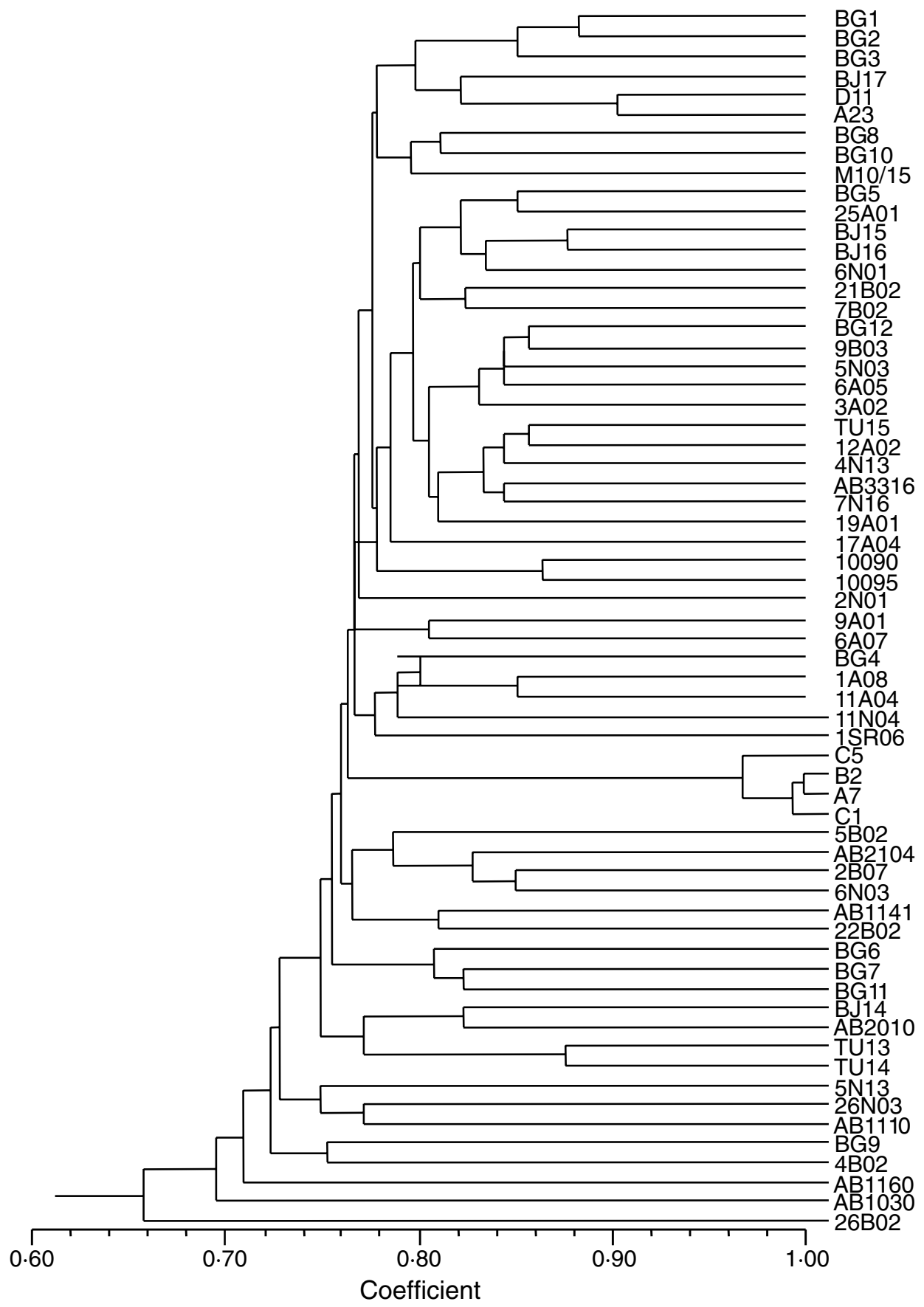

Fig. 5 Dendrogram of the environmental and known genomic species of Acinetobacter based on data from fingerprinting of the 16S-23S rRNA ISR generated using the UPGMA algorithm

to a particular DNA group based on the DFA, because of the lack of clustering with the known genomic species. However, in general, the FT-IR data appear to support the findings based on the polyphasic taxonomic approach adopted by Carr et al. (2003), to characterize these strains further. Isolates $\mathrm{A} 7, \mathrm{C} 5$ and $\mathrm{B} 2$ are all strains of $A$. baylyi, as proposed by the polyphasic study and they form a very distinct group on the basis of the FT-IR data. This taxonomic relationship is supported by the data from $16 \mathrm{~S}-$ $23 \mathrm{~S}$ rDNA ISR fingerprinting, $16 \mathrm{~S}$ rDNA sequence data and DNA-DNA hybridization data (Table 3; Carr et al. 2001a, 2003). The FT-IR analysis clusters BG3 with the 
three strains of $A$. baylyi, this may imply that BG3 belongs to the species $A$. baylyi, however, results from the 16S-23S ISR, PyMS, RAPD-PCR and DNA-DNA hybridization (Carr et al. 2001a,b; Carr et al. 2003) fail to support this observation. Strains designated 7B02 and $7 \mathrm{~N} 16$ occur in the same FT-IR cluster this supports the polyphasic taxonomic study of Carr et al. (2003), in which both strains were assigned to the new genomic species, A. tjernbergiae.

Strains 9A01, 17A04, 4N13 and 4B02 have also been placed in four newly described genomic species (Carr et al. 2003) and, FT-IR agrees with these findings. Moreover, in the present study FT-IR also groups new activated sludge isolates with these genomic species (e.g. 19AO1 and 4BO2), suggesting that there may be additional members for further characterization. Interestingly, strains $\mathrm{AB} 1110$ and $2 \mathrm{~N} 01$ which were shown to belong to the same genomic species (A. tomneri) on the basis of DNA-DNA hybridization and 16S rDNA sequencing (Carr et al. 2003) but were not grouped together by FT-IR analysis. In fact, strain AB1110 clusters very closely with BG11. Strain 5B02 was considered to belong to $A$. johnsonii from DNA-DNA hybridization data (Carr et al. 2003), the FT-IR analysis clusters this isolate with the type strain of $A$. johnsonnii (ATCC 17909T).

Table 2 gives the Biolog identifications of these environmental isolates. There was very little agreement observed between the Biolog designations and the position of the environmental isolates in the dendrogram produced from the FT-IR data (Fig. 4). Numerical taxonomic analysis of the 16S-23S rDNA ISR fingerprints of the same set of isolates analysed by FT-IR are presented in Fig. 5, allowing a direct comparison of inter-strain relationships revealed with the two methods and Table 3 shows comparisons between various techniques used to characterize a subgroup of test strains. With the exception of the distinct cluster containing A. baylyi C5, B2 and A7 with strain C1 (whose identity is unknown; Figs 4 and 5, Table 3), the relationships from 16S-23S rDNA ISR fingerprinting failed to agree with any of the previous polyphasic taxonomic conclusions (Carr et al. 2003) or the other studies characterizing the Acinetobacter (Table 3; Carr et al. 2001a,b, 2003).

\section{Concluding remarks}

The clustering illustrated by the FT-IR analysis showed limited correlation with DNA-DNA hybridization, in terms of the interspecies relationships between the known genomic species. In the majority of examples there is limited correlation between the various techniques used to identify a subset of Acinetobacter (Table 3). It is generally accepted that FT-IR is a very powerful method for discriminating bacteria at the species to subspecies levels (Naumann et al. 1991a; Schmitt and Flemming 1998; Maquelin et al. 2002). Therefore, it is possible that these discrepancies come from an inadequacy in the definitions of these genomic species of Acinetobacter, which are poorly represented by multiple strains. Indeed, some genomic species are clearly very heterogeneous and possibly comprised of multiple species. In particular the BG genomic species are diverse and from both FT-IR analyses (Fig. 2b) and 16S-23S rDNA ISR fingerprinting (Fig. 5) emerge as widely dispersed. It is likely that these attempts at finding rapid identification methods for members of this genus will be improved when multiple strains of each carefully defined genomic species were included in the analyses.

When FT-IR was applied to the selected activated sludge isolates, the data obtained from some species correlated well with the outcomes of earlier polyphasic taxonomic work with these strains (Carr et al. 2003). It is considered important to pursue this technique further as a rapid typing tool for bacteria, as suggested by Stackebrandt et al. (2002). It would be advantageous to establish a comprehensive database of known distinct Acinetobacter species to aid in the identification of unknown strains, similar to that established and evaluated successfully for coryneform bacteria (Oberreuter et al. 2002) in which it would be advantageous to include a greater number of strains for each species. In this instance FT-IR may provide the rapid identification method eagerly sought for the routine identification of Acinetobacter isolates from a wide range of habitats.

\section{ACKNOWLEDGEMENTS}

RG thanks the UK BBSRC Engineering and Biological Systems Committee for financial support.

\section{REFERENCES}

Bouffard, S.P., Katon, J.E., Sommer, A.J. and Danielson, N.D. (1994) Development of microchannel thin layer chromatography with infrared microspectroscopic detection. Analytical Chemistry 66, 1937-1940.

Bouvet, P.J.M. and Grimont, P.A.D. (1986) Taxonomy of the genus Acinetobacter with the recognition of Acinetobacter baumannii sp. nov., Acinetobacter haemolyticus sp. nov., Acinetobacter johnsonii sp. nov. and Acinetobacter junii sp. nov. and emended description of Acinetobacter calcoaceticus and Acinetobacter lmoffii. International Fournal of Systematic Bacteriology 36, 228-240.

Bouvet, P.J.M. and Jeanjean, S. (1989) Delineation of new proteolytic genospecies in the genus Acinetobacter. Research in Microbiology 140, 291-299.

Carr, E., Ward, A., Gürtler, V. and Seviour, R. (2001a) Pyrolysis mass spectrometry (PyMS) and 16S-23S rDNA spacer region fingerprinting suggests the presence of novel acinetobacters in activated sludge. Systematics and Applied Microbiology 24, 430-442. 
Carr, E., Eason, H., Feng, S., Hoogenraad, A., Croome, R., Soddell, J., Lindrea, K. and Seviour, R. (2001b) RAPD-PCR typing of Acinetobacter isolates from activated sludge systems designed to remove phosphorus microbiologically. Fournal of Applied Microbio$\log y$ 90, 309-319.

Carr, E.L., Kämpfer, P., Patel, B.K.C., Gürtler, V. and Seviour, R.J. (2003) Seven novel species of Acinetobacter isolated from activated sludge. International Fournal of Systematic and Evolutionary Microbiology 53, 953-963.

Dijkshoorn, L. (1996) Acinetobacter-microbiology. In: Acinetobacter: Microbiology, Epidemiology, Infections, Management ed. BergogneBérézin, E., Joly-Guillou, M.L. and Towner, K.J. pp. 37-69. Boca Raton: CRC Press, Inc.

Gerner-Smidt, P., Tjernberg, I. and Ursing, J. (1991) Reliability of phenotypic tests for identification of Acinetobacter species. Fournal of Clinical Microbiology 29, 277-282.

Glauninger, G., Kovar, K.A. and Hoffman, V. (1990) Possibilities and limits of an online coupling of thin-layer chromatography and FT-IR spectroscopy. Fresenius Fournal of Analytical Chemistry 338, $710-716$.

Goodacre, R. and Kell, D.B. (1996) Correction of mass spectral drift using artificial neural networks. Analytical Chemistry 68, 271-280.

Goodacre, R., Timmins, E.M., Rooney, P.J., Rowland, J.J. and Kell, D.B. (1996) Rapid identification of Streptococcus and Enterococcus species using diffuse reflectance-absorbance fourier-transform infrared spectroscopy and artificial neural network. FEMS Microbiology Letters 140, 233-239.

Goodacre, R., Timmins, É.M., Burton, R., Kaderbhai, N., Woodward, A.M., Kell, D.B. and Rooney, P.J. (1998) Rapid identification of urinary tract infection bacteria using hyperspectral, whole organism fingerprinting and artificial neural networks. Microbiology 144, 11571170 .

Helm, D., Labischinski, H., Schallehn, G., \& Naumann, D. (1991) Classification and identification of bacteria by Fourier transform infrared spectroscopy. Fournal of General Microbiology 137, 69-79.

Ibrahim, A., Gerner-Smidt, P. and Liesack, W. (1997) Phylogenetic relationship of the twenty-one DNA groups of the genus Acinetobacter as revealed by $16 \mathrm{~S}$ ribosomal DNA sequence analysis. International Fournal of Systematic Bacteriology 47, 837-841.

Janssen, P., Maquelin, K., Coopman, R., Tjernberg, I., Bouvet, P., Kersters, K. and Dijkshoorn, L. (1997) Discrimination of Acinetobacter genomic species by AFLP fingerprinting. International fournal of Systematic Bacteriology 47, 1179-1187.

Jolliffe, I.T. (1986) Principal Component Analysis. New York: SpingerVerlag.

MacFie, H.J.H., Gutteridge, C.S. and Norris, J.R. (1978) Use of canonical variates in differentiation of bacteria by pyrolysis gasliquid chromatography. Journal of General Microbiology 104, 67-74.

Magee, J.T. (1993) Whole-organism fingerprinting. In Handbook of Nem Bacterial Systematics ed. Goodfellow, M. and O'Donnell, A.G. pp. 383-427. London: Academic Press.

Manly, B.F.J. (1994) Multivariate Statistical Methods: A Primer. London: Chapman \& Hall.

Maquelin, K., Kirschner, C., Choo-Smith, L.-P., van den Braak, N., Endtz, H.P., Naumann, D. and Puppels, G.J. (2002) Identification of medically relevant microorganisms by vibrational spectroscopy. fournal of Microbiological Methods 51, 255-271.
Naumann, D., Helm, D. and Labischinski, H. (1991a) Microbiological characterisations by FT-IR spectroscopy. Nature 351, 81-82.

Naumann, D., Helm, D., Labischinski, H. and Giesbrecht, P. (1991b) The characterisation of microorganisms by Fourier-transform infrared spectroscopy (FT-IR). In Modern Techniques for Rapid Microbiological Analysis ed. Nelson, W.H.. pp. 43-96. New York: VCH Publishers.

Naumann, D., Helm, D. and Schultz, C. (1994) Characterisation and identification of micro-organisms by FT-IR spectroscopy and FT-IR microscopy. In Bacterial diversity and systematics ed. Priest, F.G., Ramos-Cormenzana, A. and Tindall, B.J. New York: Plenum Press.

Nemec, A., De Baere, T., Tjernberg, I., Vaneechoutte, M., Van der Reijden, T.J.K., \& Dijkshoorn, L. (2001) Acinetobacter ursingii sp nov and Acinetobacter schindleri sp., nov isolated from human clinical specimens. International Fournal of systematic and Evolutionary Microbiology 51, 1891-1899.

Oberreuter, H., Seiler, H. and Scherer, S. (2002) Identification of coryneform bacteria and related taxa by Fourier-transform infrared (FT-IR) spectroscopy. International fournal of Systematic and Evolutionary Microbiology 52, 91-100.

Oliver, S.G., Winson, M.K., Kell, D.B. and Baganz, F. (1998) Systematic functional analysis of the yeast genome. Trends in Biotechnology 16, 373-378.

Reasoner, D.S. and Geldreich, E.E. (1985) A new medium for the enumeration and subculture of bacteria from potable water. Applied and Environmental Microbiology 49, 1-7.

Sandt, C., Sockalingum, G.D., Aubert, D., Lepan, H., Lepouse, C., Jaussaud, M., Leon, A., Pinon, J.M. et al. (2003) Use of Fourier transform infrared spectroscopy for typing of Candida albicans strains isolated in intensive care units. Fournal of Clinical Microbio$\log y$ 41, 954-959.

Schmitt, J. and Flemming, H.C. (1998) FTIR spectroscopy in microbial and material analysis. International Biodeterioration and Biodegradation 41, 1-11.

Shute, L.A., Gutteridge, C.S., Norris, J.R. and Berkeley, R.C.W. (1988) Reproducibility of pyrolysis mass spectrometry: effect of growth medium and instrument stability on the differentiation of selected Bacillus species. Fournal of Applied Bacteriology 64, 79-88.

Stackebrandt, E., Frederiksen, W., Garrity, G.M., Grimont, P.A.D., Kampfer, P., Maiden, M.C.J., Nesme, R., Rossello-Mora, R. et al. (2002) Report of the ad hoc committee for the re-evaluation of the species definition in bacteriology. International fournal of Systematic and Evolutionary Microbiology 52, 1043-1047.

Timmins, É.M., Howell, S.A., Alsberg, B.K., Noble, W.C. and Goodacre, R. (1998a) Rapid differentiation of closely related Candida species and strains by pyrolysis mass spectrometry and Fourier transform infrared spectroscopy. Fournal of Clinical Microbiology 36, 367-374.

Timmins, É.M., Quain, D.E. and Goodacre, R. (1998b) Differentiation of brewing yeast strains by pyrolysis mass spectrometry and Fourier transform infrared spectroscopy. Yeast 14, 885-893.

Tjernberg, I. and Ursing, J. (1989) Clinical strains of Acinetobacter classified by DNA-DNA hybridisation. Acta Pathologica Microbiologica Immunologica Scandinavica 97, 596-605.

Towner, K.J. (1997) Clinical importance and antibiotic resistance of Acinetobacter spp. Fournal of Medical Microbiology 46, 721-746. 
Vandamme, P., Pot, B., Gillis, M., DeVos, P., Kersters, K. and Swings, J. (1996) Polyphasic taxonomy, a consensus approach to bacterial systematics. Microbiological Reviems 60, 407-440.

Vaneechoutte, M., Dijkshoorn, L., Tjernberg, I., Elaichouni, A., De Vos, P., Claeys, G. and Verschraegen, G. (1995) Identification of Acinetobacter genomic species by amplified ribosomal DNA restriction analysis. Fournal of Clinical Microbiology 22, 11-15.

Vila, J., Marcos, A., Llovet, T., Coll, P. and Jimenez de Anta, T. (1994) A comparative study of ribotyping and arbitrarily primed polymerase chain reaction for investigation of hospital outbreaks of Acinetobacter baumannii infection. Fournal of Medical Microbiology 41, 244-249.
Wiedmann-Al-Ahmad, M., Tichy, H.V. and Schon, G. (1994) Characterisation of Acinetobacter type strains and isolates obtained from wastewater treatment plants by PCR fingerprinting. Applied and Environmental Microbiology 60, 4066-4071.

Windig, W., Haverkamp, J. and Kistemaker, P.G. (1983) Interpretation of sets of pyrolysis mass spectra by discriminant analysis and graphical rotation. Analytical Chemistry 55, 81-88.

Winson, M.K., Goodacre, R., Woodward, A.M., Timmins, E.M., Jones, A., Alsberg, B.K., Rowland, J.J. and Kell, D.B. (1997) Diffuse relectance absorbance spectroscopy taking in chemometrics (DRASTIC) A hyperspectral FT-IR-based approach to rapid screening for metabolite overproduction. Analytica Chima Acta 348, 273-282. 